\title{
Estimation of Ground Deformation in Landslide Prone Areas Using GPS: A Case Study of Bududa, Uganda
}

\author{
Brian Makabayi, Moses Musinguzi, John Richard Otukei \\ Department of Geomatics and Land Management, Makerere University, Kampala, Uganda \\ Email: mak2brian@gmail.com
}

How to cite this paper: Makabayi, B., Musinguzi, M. and Otukei, J.R. (2021) Estimation of Ground Deformation in Landslide Prone Areas Using GPS: A Case Study of Bududa, Uganda. International Journal of Geosciences, 12, 213-232.

https://doi.org/10.4236/ijg.2021.123013

Received: February 21, 2021

Accepted: March 19, 2021

Published: March 22, 2021

Copyright (c) 2021 by author(s) and Scientific Research Publishing Inc. This work is licensed under the Creative Commons Attribution International License (CC BY 4.0).

http://creativecommons.org/licenses/by/4.0/

\begin{abstract}
Landslides are a frequent phenomenon on mountain Elgon, particularly in Bududa district on the SW side of this extinct shield volcano. Landslides have led to the destruction of property and loss of life we, therefore, need to monitor them. Monitoring how landslides build-up makes it possible to timely evacuate people and build barriers to protect property against damage by landslides. Residents in Bududa have reported cracks developing in the ground and houses. These cracks continue to grow, suggesting a future catastrophic event. Such an event may resemble the 2010 landslide in Bududa, which killed approximately 450 people and destroyed much property. In order to mitigate the consequences of a new landslide as much as possible, we monitored ground motion in Bududa in eleven stations from June 2018 to June 2019. Six-hour session GPS observations were made, and deformation was determined over the observation period, June to September 2018, September to November 2018, November 2018 to February 2019 and February to June 2019. A congruency test was performed to determine how significant the deformation was. It appeared that the ground deformation differed largely at various monitored stations, ranging from 0.004 to $0.076 \mathrm{~m}, 0.001$ to $0.067 \mathrm{~m}$ and 0 to $0.078 \mathrm{~m}$ in the East, North and vertical directions respectively. The values indicate that most slopes in the district are unstable, particularly in the wet seasons, which implies that future landslides pose a high risk for society.
\end{abstract}

\section{Keywords}

Bududa, GPS, Ground Deformation, Natural Hazards

\section{Introduction}

Landslides are one of the most frequent and dangerous geohazards affecting 
many countries today [1] [2]. Landslides are slope failures that are caused by a gravitational pull [3] and have been known to be triggered by rainfall, earthquakes, floods and human activity [4] [5] [6]. Landslides occur mostly during rainy seasons and in mountainous areas [7] [8], occurring frequently where occupants have destroyed the vegetation to the land. Landslides have been recorded to destroy property, the environment and life [8], making landslide monitoring critical [9].

Landslide monitoring of slow-moving landslides is, however, complex due to the different deformation mechanisms. Ground deformation is the change in the ground surface and this manifests as swelling, sinking or cracking. Ground deformation can be caused by magma, gas, and water moving underground or by movement of the earth's crust along fault lines [10] [11] [12]. Ground deformation is also the displacement of the ground in the horizontal, vertical and oblique directions. Ground deformation has been measured using Global Positioning Systems (GPS) over the past 15 years to detect areas at risk of landslides [13] [14]. In measuring ground deformation using GPS, the change in distances, height, angles and coordinates can be determined. The GPS measurements can either be continuous or be restricted to temporary campaigns and there are several reasons why campaign measurements are still applied according to [11]. First, these are cheaper, and there is the flexibility to where to install the GPS equipment. Second, the Continuous Operating Reference Stations (CORs) are expensive to purchase and maintain. Third, it is difficult to have a dense network when CORs are used due to the expenses involved.

Deformation using the GPS campaign technique has mostly been done at the annual level to mitigate the error biases in estimated velocities that result from short observation time-spans less than 2.5 years [15] [16] [17]. This causes us to miss out on complete characterisation of deformation patterns in landslide-prone areas at levels and seasons less than a year. The survey expenses are not put-on measurements within a year but over many years for this reason. In this study, GPS measurements were preliminarily made over precisely one year from June 2018 to June 2019 based on the rainfall seasons in Bududa. Emphasis was not put on the estimation of the deformation velocity. Still, actual deformation measured was over precisely one year. The deformation measured could be approximated as deformation velocity in a year.

The GPS measurement technique is the American satellite navigation system which provides all-day $3 \mathrm{D}$ precise coordinates of points on the earth's surface [18]. GPS accuracy and reliability ranges from millimetre to metre level depending on the type used. Geodetic dual-frequency receivers can attain millimetre accuracy while handheld GPS has metre-scale accuracy. In measuring ground deformation for purposes of landslide monitoring, geodetic dual-frequency receivers should be used. This should be done through static GPS surveys based on carrier phase measurement, which ensures effective modelling of GPS error sources. To monitor landslide development using GPS, monitor stations are installed over 
the landslide area and observations are made relative to CORs. The precise coordinates of the GPS stations are periodically determined using repeat measurements. The deformation characteristics can be derived by studying the rates of change of coordinates from survey to survey. This, in turn, can be used to analyse the geometrical properties of landslides. To attain coordinate difference at millimetre accuracy, the observation sessions are adjusted based on the network's baseline lengths, where baseline lengths less than $5 \mathrm{~km}$ are observed for 3 hours while for every additional $1 \mathrm{~km}$ an hour is added.

The current rates of ground deformation in Bududa are not well known. Estimating ground deformation rates will be used to stabilise slopes and relocation of people at high risk. In this study, we, therefore, determined the current rate of ground deformation in Bududa.

\section{Materials and Methods}

\subsection{Study Area}

This study was carried out in Bududa because of the many landslides reported in the district. Bududa district stretches from $34.26^{\circ}$ West to $34.54^{\circ}$ East and $0.96^{\circ}$ south to $1.12^{\circ}$ North and lies on the south-west slopes of Mountain Elgon. The length from south to north is $14.9 \mathrm{~km}$, and the west to east width is $29.6 \mathrm{~km}$. The average precipitation in Bududa is about $1500 \mathrm{~mm}$ per year and is bi-modal with two dry spells one in July and the other from December to February, the district experiences a long-wet season from March to June and a short-wet season from August to November, with the highest rainfall received in May. The rainfall pattern is highly controlled by altitude and areas with high altitude receive high rainfall compared to low lying areas. The district's altitude ranges from 1250 to $2850 \mathrm{~m}$, rising in the east to 3000 and $4000 \mathrm{~m}$ at the peak of Mountain Elgon as shown in Figure 1. The district has generally steep slopes above 40 degrees with V-shaped valleys.

Part of the district is covered by Mountain Elgon National Park which is a protected ecosystem. Additionally, the district has about twenty-four small rivers flowing from the Mountain Elgon peak. The rivers flow through the cultivated and degraded habited slopes and valleys to river Manafwa and then into Lake Kyoga. The degraded slopes are due to the high population growth rate estimated at $3.8 \%$ per annum.

The predominant soil type in Bududa classified by the Food Agriculture Organization (FAO) is Nitisols, Luvisols, Gleysols and Agric Ferralsols. In Bududa, Central are iron-rich Rhodic Nitisols red in colour and consist of calcium carbonate, giving them a high cohesion. These are permeable to water and plant roots limiting water runoff due to magnetite and hematite constituents. This makes these soils very stable and less affected by deformation and landslides. North and west of the district are Lixisols, Cambisols, Nitisols and Acrisols soils with many shear planes 0.2 to $2 \mathrm{~m}$ within the soil and the parent rock. These are 


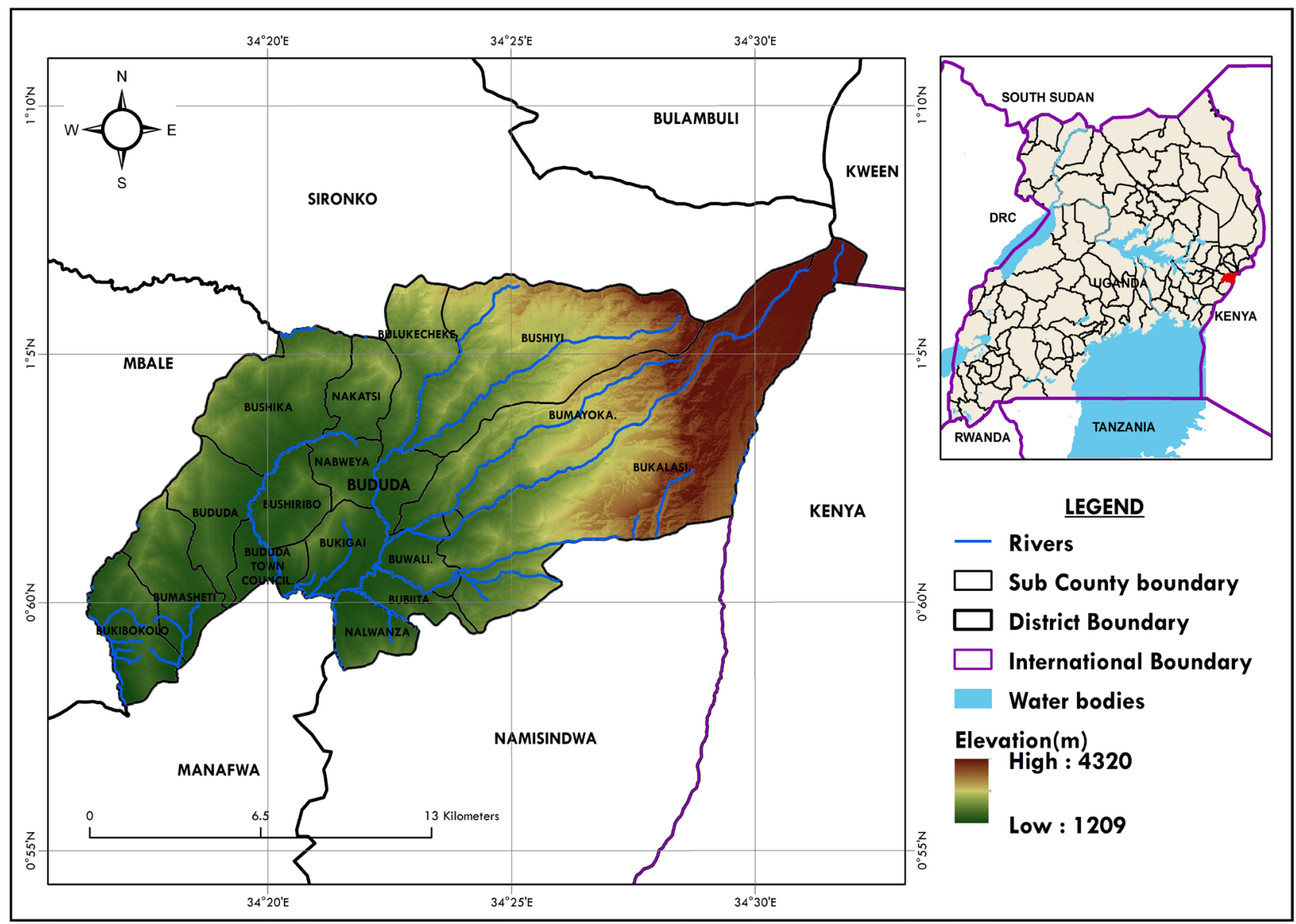

Figure 1. Location of Bududa district, its sub-counties, rivers, and elevation.

at the clay layering horizons and cause surface cracks which widen with an increase in rainfall. In the east are Ferralsols, Lixisols, Gleysols and Acrisols which deform under steep slopes and heavy rainfall due to the excessive soil degradation.

\subsection{Data Collection}

Reconnaissance was done to determine the points where the eleven GPS stations were installed. The GPS stations were placed in areas at high risk of landslides as shown Figure 2. This was achieved by installing stations in areas that had previously experienced landslides. The deformation rates were measured using campaign GPS from $15^{\text {th }}$ June 2018 to $15^{\text {th }}$ June 2019 as shown in Table 1 . The monitor stations measured 50 by $50 \mathrm{~cm}$ wide and a metre deep fitted with a metallic bar in the centre. The GPS monitor stations were established in areas with good satellite coverage, a wide satellite view angle and minimal overhead obstructions to improve the accuracy of position fixing.

To determine the predominant satellite geometry and coverage at each proposed GPS station, a handheld GPS was used and the satellite geometry was visualised through the sky plots. It was ensured that the Dilution of Precision 
(DOP) at each station was less than 2. Furthermore, the handheld GPS was used to capture coordinates of the proposed GPS station points, and baseline lengths of the network were determined. Observations were then made using Promark 800 Dual-frequency Geodetic Ashtech GPS receivers in 6-hour sessions and Antennas recording data at a 30-second interval following the observation sessions shown in Table 1 . In each month, of the five months in which observations were made, two sessions were made of five and six stations respectively.

The GPS Stations at Bubiita, Bukalasi, Bulucheke, Bumayoka, Nakatsi, Bududa, Bukigai, Bukibokolo, Bushiyi, Bududa Town Council and Bushika have been abbreviated as BUBI, BUKA, BULU, BUMA, NAKA, BUDU, BUKI, BUKO, BUSY, BUTC and BUSH for ease of naming in the sections onwards. The observation sessions were for six hours and this met that most of the GPS observation biases cancelled out. Additionally, the short baseline lengths in the network, 5 to $7 \mathrm{~km}$, enabled the fixing of coordinates with relatively high accuracy. Short baseline length ensured that spatially correlated GPS errors cancel out with differencing. It should be noted that with short baseline lengths, high GPS reliability is achieved even with short observation sessions, according to [11]. It means that the 6-hour observations were sufficient to attain the desired measurement accuracy..

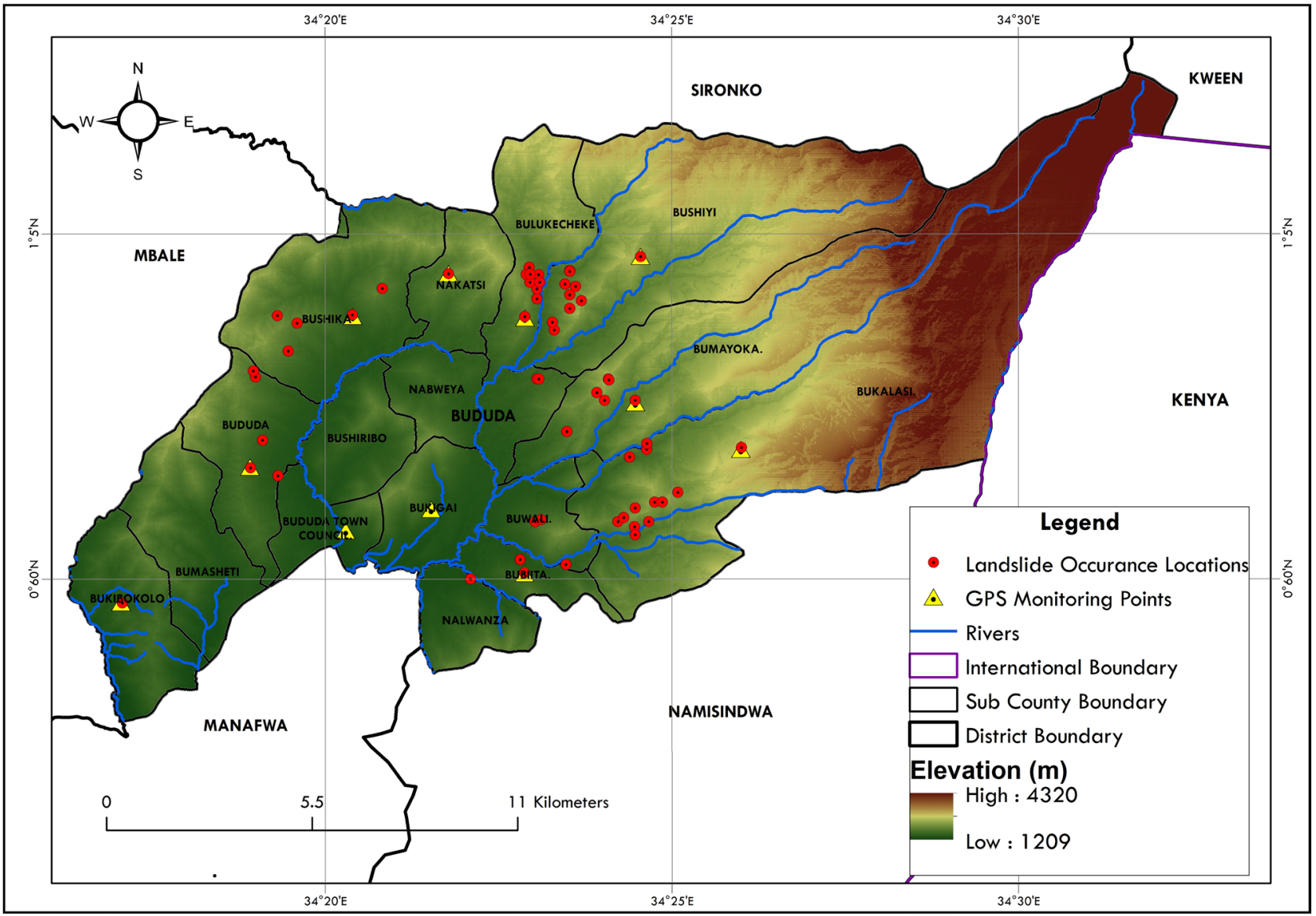

Figure 2. Landslide occurrence locations, GPS stations, rivers, elevation and subcounties in Bududa district. 


\subsection{Data Processing}

The GPS stations' coordinates were computed using double ionosphere-free linear combinations with six reference stations shown in Figure 3. The main processing parameters were a satellite cut-off angle of $15^{\circ}$, an observation sampling rate of 30 seconds, the maximum observation strategy for creating the baseline, the Quasi-Ionosphere Free strategy to fix the ambiguity, and the modelling of the tropospheric delay with the Global Mapping Function (GMF). The zenith delay corrections were estimated based on the wet-GMF mapping function at 2-hour intervals [19].

Table 1. The year, month, day and times of the observation sessions of the campaign measurements made over the 11 GPS stations in Bududa from June 2018 to June 2019.

\begin{tabular}{|c|c|c|c|c|c|c|c|c|c|c|}
\hline \multirow{3}{*}{ Station } & \multicolumn{10}{|c|}{ YearlMonth dayl Session (day of the year)/Observation Time (Initial and Final hours) } \\
\hline & \multicolumn{6}{|c|}{2018} & \multicolumn{4}{|c|}{2019} \\
\hline & Jun 15 & Jun 16 & Sept 01 & Sept 02 & Nov 03 & Nov 04 & Feb 23 & Feb 24 & Jun 15 & Jun 16 \\
\hline & 166 & 167 & 244 & 245 & 307 & 308 & 054 & 055 & 166 & 167 \\
\hline \multirow[t]{2}{*}{$B U B I$} & & $10: 56$ & 09:16 & & $11: 40$ & & 09:39 & & 09:58 & \\
\hline & & $17: 00$ & $15: 57$ & & $18: 45$ & & $17: 00$ & & $15: 58$ & \\
\hline \multirow[t]{2}{*}{$B U K A$} & $12: 02$ & & $10: 42$ & & & $11: 56$ & $10: 59$ & & $11: 13$ & \\
\hline & 18:03 & & $16: 42$ & & & $16: 03$ & $17: 01$ & & $17: 13$ & \\
\hline \multirow[t]{2}{*}{$B U L U$} & $12: 07$ & & $10: 37$ & & $12: 15$ & & $10: 55$ & & $11: 05$ & \\
\hline & $18: 22$ & & $16: 45$ & & $18: 21$ & & $16: 57$ & & $17: 12$ & \\
\hline \multirow[t]{2}{*}{$B U M A$} & $10: 23$ & & $10: 37$ & & $12: 17$ & & 11:02 & & 11:06 & \\
\hline & $18: 42$ & & $16: 50$ & & $18: 20$ & & $17: 06$ & & $17: 09$ & \\
\hline \multirow[t]{2}{*}{$N A K A$} & $12: 07$ & & $10: 37$ & & $12: 15$ & & $10: 54$ & & 11:06 & \\
\hline & $18: 37$ & & $16: 46$ & & $18: 23$ & & $16: 11$ & & $17: 10$ & \\
\hline \multirow[t]{2}{*}{$B U D U$} & $12: 10$ & & & 09:04 & & $12: 03$ & & 08:30 & & 09:01 \\
\hline & $18: 20$ & & & $15: 13$ & & $16: 15$ & & $14: 33$ & & $15: 06$ \\
\hline \multirow[t]{2}{*}{$B U K I$} & & $10: 57$ & & 09:02 & & $12: 00$ & & 08:29 & & 08:59 \\
\hline & & $17: 05$ & & $15: 03$ & & $16: 02$ & & $14: 36$ & & 15:07 \\
\hline \multirow[t]{2}{*}{ BUKO } & & $10: 58$ & & 08:43 & & $12: 00$ & & 08:30 & & 09:00 \\
\hline & & $17: 10$ & & $14: 43$ & & $16: 04$ & & $14: 32$ & & $15: 06$ \\
\hline \multirow[t]{2}{*}{$B U S Y$} & & $10: 57$ & $10: 37$ & & $12: 14$ & & $10: 54$ & & & $11: 47$ \\
\hline & & $17: 02$ & $16: 51$ & & $18: 22$ & & $17: 01$ & & & $14: 01$ \\
\hline \multirow[t]{2}{*}{$B U T C$} & & $10: 51$ & & 09:01 & $12: 11$ & & & $08: 28$ & & 09:03 \\
\hline & & $16: 52$ & & 15:05 & $18: 11$ & & & $14: 38$ & & $15: 42$ \\
\hline \multirow[t]{2}{*}{ BUSH } & $12: 07$ & & & 09:06 & & 11:59 & & 08:31 & & 08:58 \\
\hline & $18: 23$ & & & $15: 19$ & & $16: 02$ & & $14: 37$ & & $15: 08$ \\
\hline
\end{tabular}




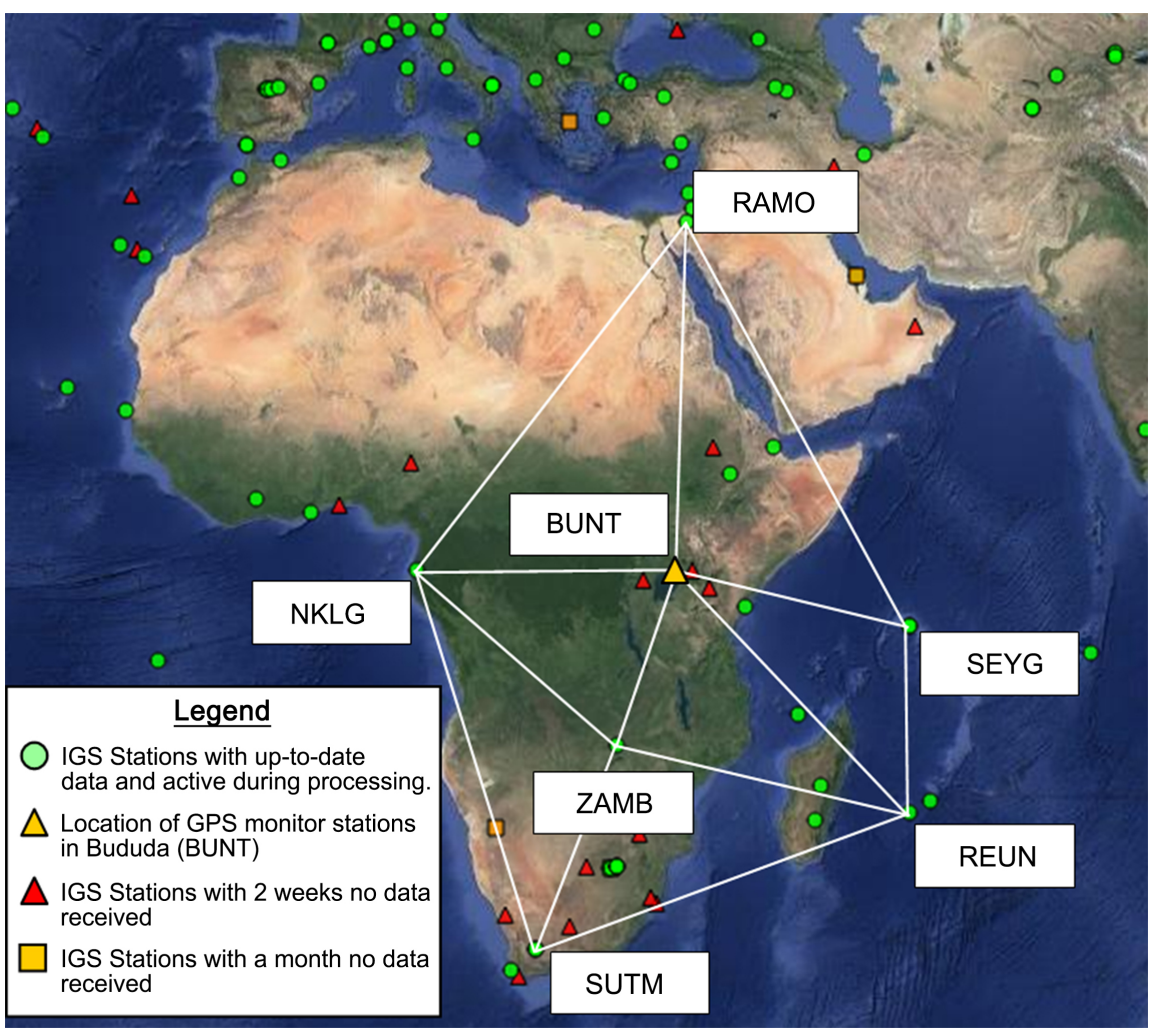

Figure 3. The International Geodetic Stations (IGS) RAMO, NKLG, ZAMB, SUTM, REUN, SEYG used in processing the GPS observation network in Bududa. The GPS observation network in Bududa has been abbreviated as BUNT.

The first, second and third-order ionospheric effects were modelled using the ionospheric linear combination of L1 and L2. L1 is the longer wavelength carrier phase band and L2 the shorter carrier phase band of the GPS signal. The ground antenna and satellite phase Centre calibration were based on the IGS14 phase-Centre variation model, whereas the tidal displacements were derived from a model of the International Earth Rotation and Reference Systems (IERS) conventions 2010 [20] [21] [22]. The effect of the atmosphere was negated using the atmospheric loading model [12] [23] [24] [25]. The satellite trajectories and earth orientations were modelled using the available IGS products, as shown in Figure 3 \& Figure 4. The phase processing to estimate the cycle slips was through triple-differencing of the observation baselines. The cycle slips were then fixed by the analysis of different linear combinations of L1 and L2 combination. If the cycle slips were hard to fix, the bad data points were removed and new ambiguities were calculated. Data screening was further performed based on the weighted post fit residuals, and outliers were removed. The data cleaning was performed at a sampling rate of 30 seconds, and elevation-dependent weighting was applied based on $1 / \sin (e)^{2}$, where $e$ is the elevation angle of the satellite. In estimating the final coordinates of the GPS stations, coordinate constraints were made at the reference stations. The horizontal and vertical component constraints were $1 \mathrm{~mm}$ and $2 \mathrm{~mm}$, respectively. The ambiguities were resolved using 
the baseline-by-baseline mode using the code-based strategy for baselines between 180 and $6000 \mathrm{~km}$, phase-based L5/L3 for baselines between 18 and 200 $\mathrm{km}$, Quasi Ionosphere Free (QIF) strategy for baselines between 18 and $2000 \mathrm{~km}$, and direct L1/L2 for baselines between 0 and $20 \mathrm{~km}$ as shown in Figure 4 .

To statistically check the significance of deformation, a congruency test was performed on the three-dimension movement of the GPS stations. The three-dimension movement is a function of the movement in the east, north and vertical directions as is shown in Equation (1), where $\delta d_{i j}$ is the movement of a point from time $i$ to $j$.

$$
\delta d_{i j}=\left(d E_{i j}^{2}+d N_{i j}^{2}+d h_{i j}^{2}\right)^{1 / 2}
$$

The null hypothesis of the test was that there was no movement between the time $i$ and $j$ and therefore

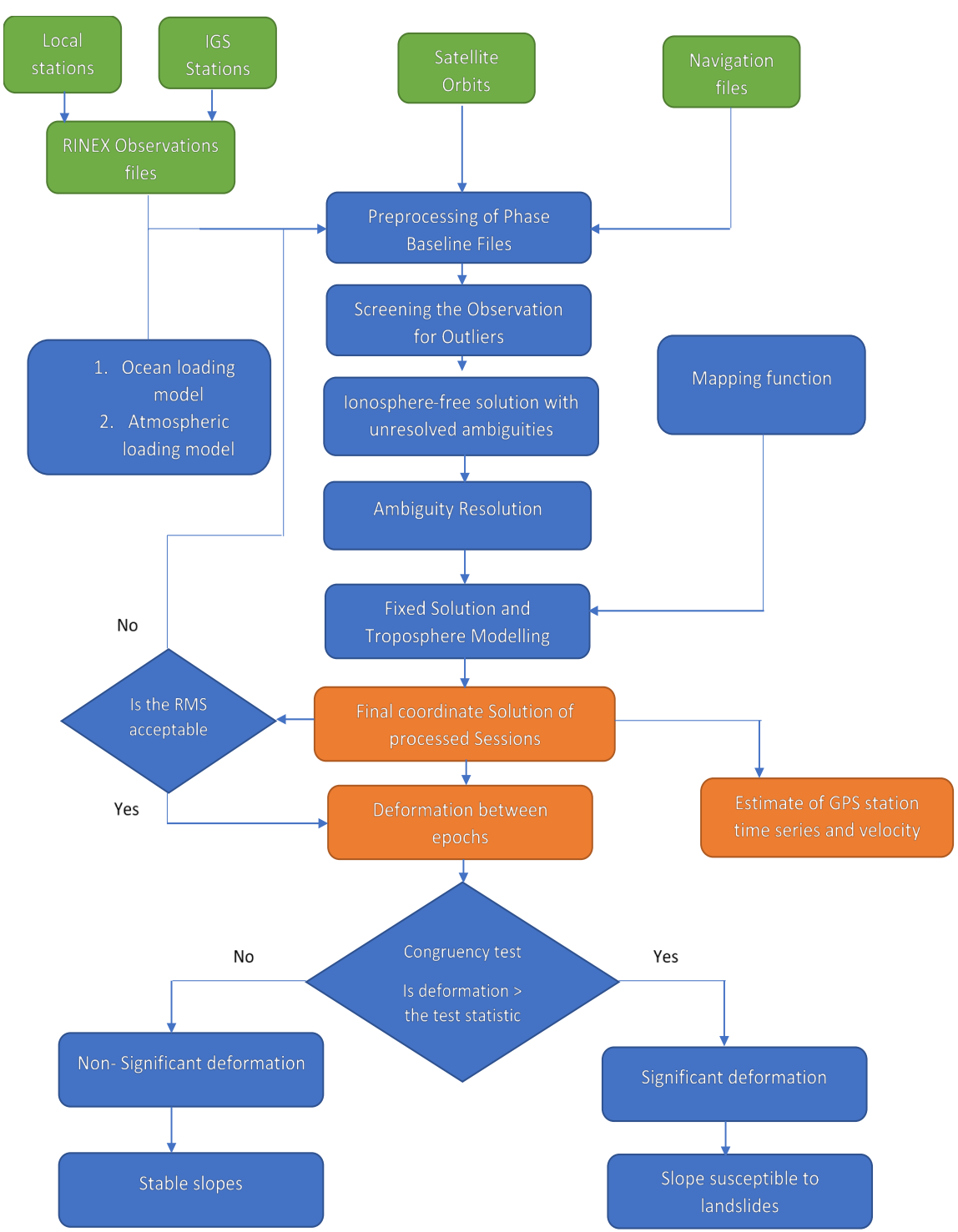

Figure 4. The GPS processing methodology. 
Null hypothesis

$$
H_{0}: \delta d_{i j}=0
$$

Alternative hypothesis

$$
H_{a}: \delta d_{i j} \neq 0
$$

The test statistic used was

$$
\boldsymbol{T}=\delta d_{i j} /\left(\sigma \text { of } \delta d_{i j}\right)
$$

$H_{0}$ is true when the test statistic has a student's $t$-distribution and the region where the null hypothesis is rejected.

$$
|\boldsymbol{T}|>t_{d f, \alpha / 2}
$$

where $d f$ is the degree of freedom, and $\alpha$ is the significance level for the test. In this study, $d f \rightarrow \infty$ (infinity), because the GPS baselines were determined through 6-hour observations collecting data at a 30 -second interval. It should be noted that if the $\mathrm{t}$-distribution has an infinite degree of freedom, the distribution is a normal distribution [10]. A 99\% (i.e., $\alpha=1 \%$ ) confidence interval was used in this study, where the critical value was calculated as $t_{\infty, 0.005}$ equal to 2.576 . The computed test statistic was compared with the critical value and where the test statistic was higher than the critical value, the null hypothesis was rejected, and it met that the GPS station experienced significant deformation. The reverse was true when the test statistic was lower than the critical value, where the alternative hypothesis was rejected, and it met that the GPS station did not experience significant deformation.

\section{Results and Discussions}

\subsection{Results}

Deformation was determined from June 2018 to June 2019 as is shown in Tables 2-4 and Figure 5 and between the five consecutive observations June 2018, September 2018, November 2018, February 2019 and June 2019 as is shown in Figure 6 and Table 4. Campaign GPS measurements are normally done at an annual scale, probably due to cost or thought that deformation variation within a year is not significant to necessitate observations within a year [26] [27]. Therefore, this study investigated the effect of shortening the time between campaign observations to a monthly level in characterizing ground deformation magnitudes [11].

The least and highest deformation in the east was $0.004 \mathrm{~m}$ at BUKA and 0.076 $\mathrm{m}$ at NAKA stations, as shown in Table 2. BUKA BULU and BUKI stations, experienced the least deformation in the east $\leq 0.007 \mathrm{~m}$, while NAKA and BUTC experienced the highest deformation of $0.076 \mathrm{~m}$ and $0.071 \mathrm{~m}$. The Root Mean Square (RMS) at which deformation in the east direction estimated was about 1 $\mathrm{mm}$ except at BUBI and BUTC where the RMS is 2.8 and $1.5 \mathrm{~mm}$ respectively. The least and highest deformation in the north was $0.001 \mathrm{~m}$ at BULU and 0.067 $m$ at NAKA. The Stations at BULU, BUKI and BUSY experienced the least de- 
formation $\leq 0.002 \mathrm{~m}$. The RMS at which the north deformation was fixed was also about $1 \mathrm{~mm}$ except at BUBI and BUTC stations with RMS of 3.1 and 2.5 $\mathrm{mm}$. The least and highest deformation in height was 0 at BUKA and $0.078 \mathrm{~m}$ at BUMA. The BUKA station did not experience deformation in height whereas stations at BUMA, NAKA and BUTC experienced the highest deformation of $0.078,0.072$ and $0.068 \mathrm{~m}$ respectively. The RMS of the computed deformation in height was also about $1 \mathrm{~mm}$ except for BUBI and BUTC where the RMS was 1.8 $\mathrm{mm}$ and $3.6 \mathrm{~mm}$.

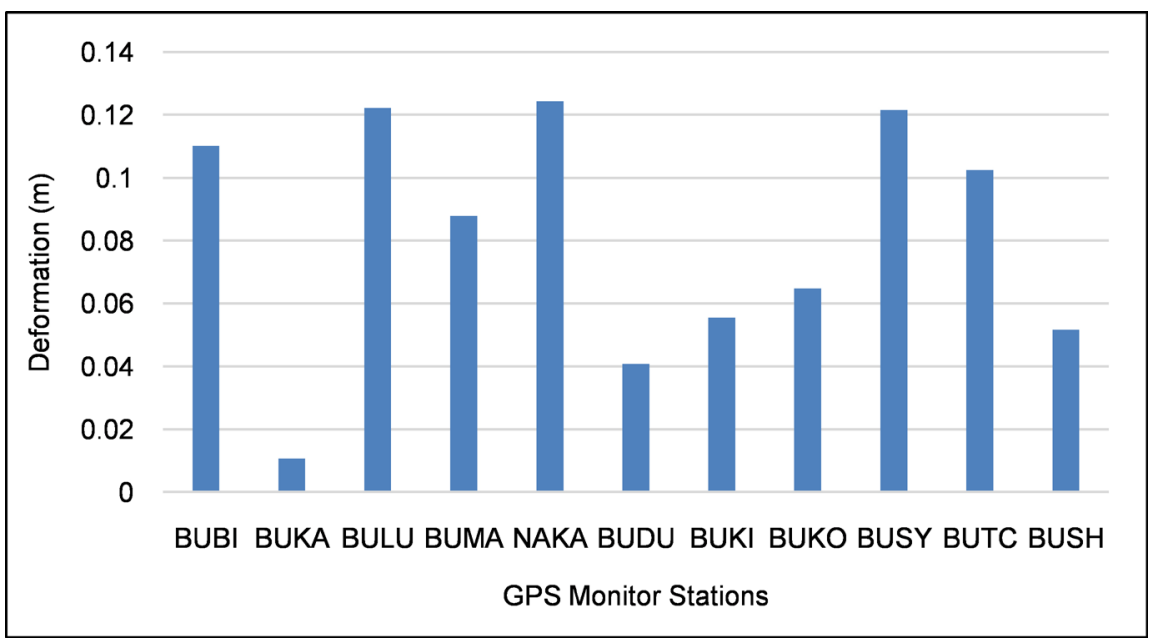

Figure 5. A graph showing ground deformation of 11 GPS stations in Bududa district from June 2018 to June 2019.

Table 2. The Estimated Ground Deformation in the East, North and Height for eleven (11) GPS monitor stations from June 2018 to June 2019.

\begin{tabular}{|c|c|c|c|c|c|c|}
\hline \multirow{2}{*}{ Station } & \multicolumn{3}{|c|}{ Deformation } & \multicolumn{3}{|c|}{ RMS (m) } \\
\hline & East & North & Height & East & North & $\mathrm{Up}_{\mathrm{p}}$ \\
\hline BUBI & 0.015 & 0.033 & 0.014 & 0.0028 & 0.0031 & 0.0018 \\
\hline BUKA & 0.004 & 0.010 & 0.000 & 0.0007 & 0.0009 & 0.0007 \\
\hline BULU & 0.007 & 0.001 & 0.022 & 0.0007 & 0.0008 & 0.0007 \\
\hline BUMA & 0.029 & 0.028 & 0.078 & 0.0009 & 0.0007 & 0.0008 \\
\hline NAKA & 0.076 & 0.067 & 0.072 & 0.0008 & 0.0008 & 0.0008 \\
\hline BUDU & 0.038 & 0.009 & 0.012 & 0.0006 & 0.0009 & 0.0007 \\
\hline BUKI & 0.007 & 0.002 & 0.055 & 0.0008 & 0.0008 & 0.0008 \\
\hline BUKO & 0.028 & 0.030 & 0.050 & 0.0007 & 0.0005 & 0.0006 \\
\hline BUSY & 0.042 & 0.001 & 0.014 & 0.0006 & 0.0006 & 0.0006 \\
\hline BUTC & 0.071 & 0.029 & 0.068 & 0.0015 & 0.0025 & 0.0036 \\
\hline BUSH & 0.018 & 0.030 & 0.038 & 0.0006 & 0.0008 & 0.0005 \\
\hline
\end{tabular}


Table 3. The congruency test performed on the 11 GPS stations to determine the significance of deformation of all the stations from June 2018 to June 2019.

\begin{tabular}{ccccc}
\hline Stations & $\delta d_{i j}$ & $\sigma$ of $\delta d_{i j}$ & $\mathrm{~T}=2.576$ & $\begin{array}{c}\text { Significant } \\
\text { deformation }\end{array}$ \\
\hline BUBI & 0.110 & 0.024 & 4.629 & YES \\
BUKA & 0.011 & 0.038 & 0.282 & NO \\
BULU & 0.122 & 0.018 & 6.975 & YES \\
BUMA & 0.088 & 0.051 & 1.737 & NO \\
NAKA & 0.124 & 0.043 & 2.922 & YES \\
BUDU & 0.041 & 0.011 & 3.654 & YES \\
BUKI & 0.055 & 0.011 & 5.002 & YES \\
BUKO & 0.065 & 0.005 & 11.810 & NES \\
BUSY & 0.121 & 0.066 & 1.853 & NO \\
BUTC & 0.102 & 0.062 & 1.660 & NO \\
BUSH & 0.052 & 0.022 & 2.343 &
\end{tabular}

Table 4. The congruency test showing the significance of the ground deformation in the four time-spans, June to September 2018 (1 - 2), September to November 2018 (2 - 3), November 2018 to February 2019 (3 - 4) and February to June 2019 (4 - 5).

\begin{tabular}{|c|c|c|c|c|c|c|c|c|c|c|c|c|}
\hline $\begin{array}{c}\text { GPS } \\
\text { Stations }\end{array}$ & $\begin{array}{c}\delta d_{i j} \\
(1-2)\end{array}$ & $\begin{array}{c}\sigma \text { of } \\
\delta d_{i j}\end{array}$ & $\begin{array}{c}T=\left(\delta d_{i j}(1-2) /\right. \\
\left.\sigma \text { of } \delta d_{i j}\right) \\
=2.574\end{array}$ & $\begin{array}{c}\delta d_{i j} \\
(2-3)\end{array}$ & $\begin{array}{c}\sigma \text { of } \\
\delta d_{i j}\end{array}$ & $\begin{array}{c}T=\left(\delta d_{i j}(2-3) /\right. \\
\left.\sigma \text { of } \delta d_{i j}\right) \\
=2.574\end{array}$ & $\begin{array}{c}\delta d_{i j} \\
(3-4)\end{array}$ & $\begin{array}{l}\sigma \quad \text { of } \\
\delta d_{i j}\end{array}$ & $\begin{array}{c}T=\left(\delta d_{i j}(3-4) /\right. \\
\left.\sigma \quad \text { of } \delta d_{i j}\right) \\
=2.574\end{array}$ & $\begin{array}{c}\delta d_{i j} \\
(4-5)\end{array}$ & $\begin{array}{l}\sigma \text { of } \\
\delta d_{i j}\end{array}$ & $\begin{array}{c}T=\left(\delta d_{i j}(4-5) /\right. \\
\left.\sigma \quad \text { of } \delta d_{i j}\right) \\
=2.574\end{array}$ \\
\hline BUBI & 0.191 & 0.034 & 5.533 & 0.083 & 0.008 & 10.173 & 0.139 & 0.049 & 2.826 & 0.06 & 2.278 & 0.264 \\
\hline BUKA & 0.056 & 0.004 & 14.962 & 0.005 & 0.007 & 0.803 & 0.053 & 0.059 & 0.913 & 0.036 & 0.025 & 1.450 \\
\hline BULU & 0.047 & 0.050 & 0.946 & 0.103 & 0.026 & 3.949 & 0.124 & 0.046 & 2.702 & 0.070 & 0.083 & 0.847 \\
\hline BUMA & 0.077 & 0.024 & 3.246 & 0.027 & 0.006 & 4.439 & 0.049 & 0.013 & 3.780 & 0.080 & 0.036 & 2.198 \\
\hline NAKA & 0.136 & 0.004 & 36.369 & 0.112 & 0.013 & 8.930 & 0.067 & 0.011 & 6.232 & 0.179 & 0.019 & 9.478 \\
\hline BUDU & 0.022 & 0.006 & 3.575 & 0.041 & 0.032 & 1.297 & 0.036 & 0.027 & 1.347 & 0.026 & 0.002 & 10.786 \\
\hline BUKI & 0.044 & 0.001 & 31.289 & 0.021 & 0.029 & 0.707 & 0.527 & 0.255 & 2.064 & 0.062 & 0.294 & 2.108 \\
\hline BUKO & 0.072 & 0.007 & 10.780 & 0.075 & 0.016 & 4.666 & 0.080 & 0.009 & 8.788 & 0.050 & 0.027 & 1.867 \\
\hline BUSY & 0.092 & 0.006 & 14.343 & 0.073 & 0.005 & 14.011 & 0.066 & 0.188 & 0.354 & 0.072 & 0.134 & 0.541 \\
\hline BUTC & 0.032 & 0.029 & 11.095 & 0.181 & 0.038 & 4.806 & 0.213 & 0.050 & 4.216 & 0.101 & 0.047 & 2.149 \\
\hline BUSH & 0.019 & 0.011 & 1.667 & 0.043 & 0.026 & 1.660 & 0.047 & 0.004 & 11.111 & 0.049 & 0.005 & 10.781 \\
\hline
\end{tabular}




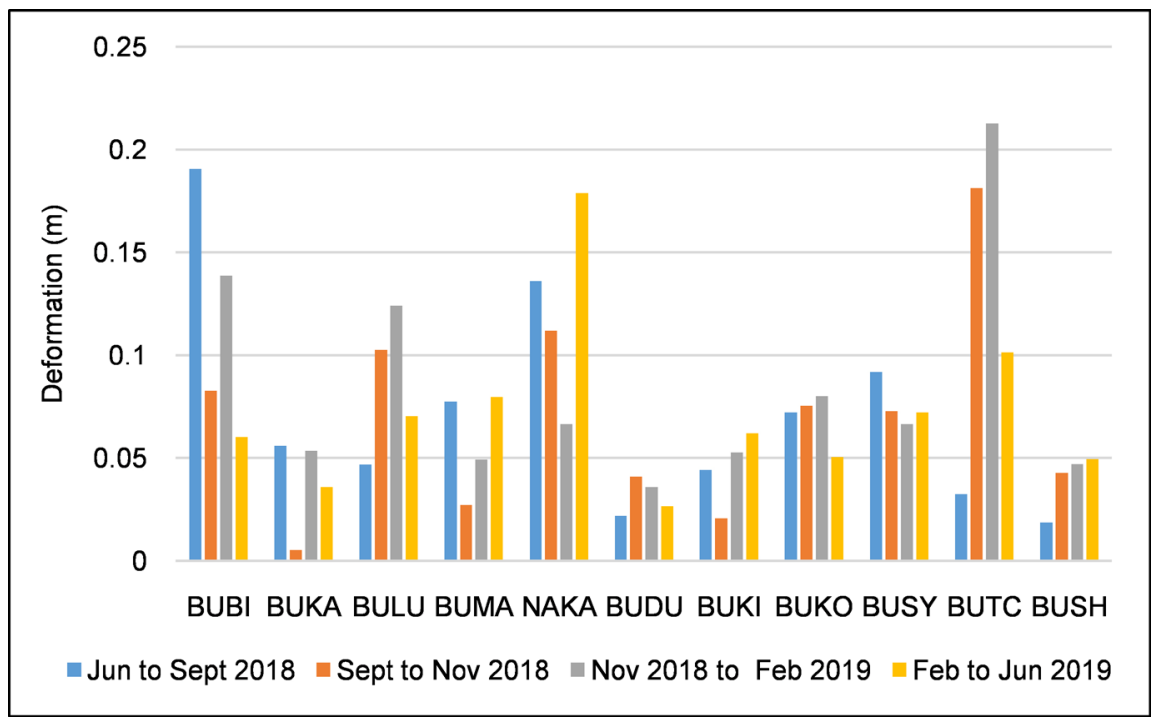

Figure 6. Ground deformation magnitudes for 11 GPS stations in Bududa District for four time-spans between June 2018 and June 2019.

The deformation in three dimensions was then computed based on Equation (1) for all the stations between June 2018 and June 2019. It was observed that GPS monitor stations at BUBI, BULU, BUMA, NAKA, BUSY, and BUTC experienced high deformation above $0.08 \mathrm{~m}$ as is shown in Figure 5, while BUKA, BUDU, BUKI, BUKO and BUSH experienced deformation below $0.07 \mathrm{~m}$. BUKI and BUKO have not experienced many landslides in the past which justifies the low deformation. However, BUKA, BUDU and BUSH have experienced landslides in the past and the low deformation during this study may only imply a high fluctuation in the deformation at such points. This further may mean that these stations could experience high deformation in another monitoring scheme. BUKI experienced deformation less than $0.06 \mathrm{~m}$ due to the soils in Bukigai that are permeable to water and plant roots in the $2 \mathrm{~m}$ topsoil. Furthermore, the soil in Bukigai, experiences limited runoff except on unprotected slopes exceeding 15\% slopes [28]. The soils are Rhodic Nitisols very stable and are not affected by landslides. These soils have been drilled and it was observed that they are weathered down up to 40 meters. They are derived from magnetite and hematite minerals rich in iron and the stability of this soil may be due to the cohesion resulting from cementing minerals like calcium carbonate [29]. This phenomenon has also been observed in New Zealand where the calcium carbonate minerals in the rocks and soils have increased stability [28]. BUKO has a low altitude, slope and receives less rainfall addition to the soils with a high sand content. These conditions make the soils stable hence the low deformation experienced. The low deformation is usually as a result of minimal collapse of the soil to fill the pore spaces left behind with drained water in dry weather.

BUDU and BUSH with low deformation of $0.041 \mathrm{~m}$ and $0.052 \mathrm{~m}$ respectively are characterized by Cambisols, Nitisols, Acrisols and Lixisols soils high in clay content similar to soils in Bukigai. They do not have horizon stratification 
and are not significantly affected by water stagnation properties that exist in landslide-prone areas. As observed by [30], landslides in BUDU and BUSH have been estimated to re-occur after 100. This indicates that ground deformation in these areas is slow and incrementally builds over time. These areas are therefore, characterized by cracks that slowly expand as evidenced by the low deformation magnitudes. BUKA experienced low deformation due to it having experienced significant deformation which led to the March 2010 landslide. The massive landslide washed away the thin top unstable soil leaving behind a thinner but more stable soil layer.

BULU, NAKA and BUSY stations located in the eastern experienced very high deformation above $0.12 \mathrm{~m}$. There are many landslides in the east as reported by [28] [29] [30]. The many landslides are most likely due to the high deformation magnitudes experienced. The high deformation magnitudes in the east of Bududa district are attributed mostly to terracing and cultivation of steep slopes and slope concavity [28] [29] [30] [31]. The soils in the east additionally have high infiltration rates which have led to the fast flow of water into soils down the profiles. At the lower profiles, the high clay content causes the water to stagnate and this in conjunction with steep slopes, cause high ground deformation.

To test the significance of the measured deformation, a congruency test was carried out which showed that five stations, BUBI, BULU, NAKA, BUDU, BUKI and BUKO had significant deformation as shown in Table 3. The other stations at BUKA, BUMA, BUSY, BUTC and BUSH did not experience substantial deformation during this observation period. It should however be noted that these stations not having significant deformation during this observation period does not mean that they are stable and safe areas. Landslides have been identified in some of these areas before and not experiencing significant deformation during this observation period may mean two things. First, deformation varies significantly in these areas, for example, it has been observed by the locals that when a landslide occurs in an area, it will take some time before another landslide occurs. This could mean or imply that when a landslide occurs, the unstable soil is washed away and stable soil is left behind. This could be the case with the station BUKA that did not experience significant deformation during this observation period but it is here that the largest landslide in the district's history has been recorded [32]. Secondly, the deformation may be minimal but incremental, this deformation will build and as evidenced with cracks and landslides will occur 5 10 years.

To better understand the deformation magnitudes over short time-spans, deformation magnitudes were determined between four time-spans to determine whether deformation magnitudes varied significantly within these time-spans. It is essential to determine deformation magnitudes over these short-time spans when an area has varying seasons in a year which seasons may affect ground deformation. It can be observed that the deformation magnitudes between June and September 2018, September and November 2018, November 2018 and Feb- 
ruary 2019 and February and June 2019 in Bududa were generally below $0.1 \mathrm{~m}$ for all the GPS stations except for stations BUBI, BULU, NAKA and BUTC as shown in Figure 6. BUBI had a high deformation from June to September 2018, BULU from November 2018 to February 2019, NAKA from February to June 2019 and BUTC from November 2018 to February 2019. These are high deformation values when compared to other landslide-struck regions in the world [14]. Ground deformation in Bududa is very complex and varies from one observation station to another. This is associated with the change in altitude, soil type, soil texture, slope, land cover and human population. It also varies throughout the year and this could be associated with the variation in the rainfall patterns [33] [34] [35] [36] [37]. It would be expected that deformation should be high only during the long and short wet seasons which in Bududa are March to June and August to October respectively and low in the long and short dry seasons which is November to February and July respectively. This is expected because during the wet season the rainwater fills the soil pores and is stagnant at different clay layers. Furthermore, given the steep slopes, there is an increase in the weight of the soil hence ground deformation occurs. However, this is not necessarily as is observed in our study, June to September 2018, September to November 2018 and February to June 2019 which coincide with the wet season and November 2018 to February 2019 a dry season.

In the dry seasons, the deformation is expected to be minimal. Deformation during the dry seasons is due to the slow drainage or further infiltration of water down the soil layers and the soil moisture evaporation when temperatures increase. The soil collapses over air spaces left behind after evaporation due to soil pressure. This phenomenon is largely not disastrous but landslides have been reported in Bududa during the dry season which shows that these sorts of deformation can at times pose a risk to the communities.

The stations in BUMA, NAKA, BUKI and BUSH experienced the highest deformation from February to June 2019 which coincides with the long rainy season in Bududa. While stations at BULU, BUKO and BUTC experienced the most significant deformation from November 2018 to February 2019. It can further be observed that deformation during this long dry period reached $0.213 \mathrm{~m}$ at BUTC. Implying that Bududa too experienced high deformation in the dry season. Stations at BUBI, BUKA and BUSY experienced the highest deformation from June to September 2018 that spans from the end of the long-wet season in June through the short dry season in July and the start of the short-wet season in September. High deformation values at BUTC from September to November 2018 and November 2018 to February 2019 could be due to close proximity of this station to a small river. The station is not on a steep slope but about $15 \mathrm{~m}$ from a small river. The cause of deformation of points close to river banks is normally due to the wash away of river banks over time through soil erosion causing lines of weakness and hence deformation at such points. This however may not be the case here due to the station being located $15 \mathrm{~m}$ away (not very 
close) from the river but may be due to draining of water through the lower soil layers to the river that is at a lower level. From what we observe here, it is clear and evident that when we only analyze deformation at an annual level, we miss out on complete characterization of deformation patterns at seasonal level in landslide-prone areas.

A congruency test was also carried out and it showed that June to September 2018, all stations had significant deformation except the stations at BULU and BUSH. The deformation at these stations may be attributed to the water infiltration during the rains. When it rains, the rainwater infiltrates the soil and soils move along lines of weakness as a function of the slope. Additionally, when the dry season starts in July, the soil moisture evaporates leaving spaces behind and hence soil collapse and deformation occurs. When the second rains come, the infiltration process begins afresh.

Deformation at BULU and BUSH was not significant and this may be attributed to the fact that these points have experienced significant deformation in the past and were stable during this period. This is the case because cracks and landslide scars were observed around BUSH and BULU stations. The other reason could be that this area's soil characteristics have a slowed reaction to rainwater infiltration and evaporation.

September to November 2018, a time-span that coincides with the short-wet season, the stations that did not have significant deformation were BUKA, BUDU, BUKI and BUSH. This shows that stations BUKA, BUDU and BUKI which had significant deformation from June to September 2018 experienced slowed deformation from September to November 2018. This showed that stations in Bududa have varying deformation within a year as a result of change in seasons. The BUSH station compared to other stations did not have significant deformation both from June to September 2018 and September to November 2018.

November 2018 to February 2019, all the other stations experienced significant deformation except BUKA, BUDU, BUKI and BUSY. We observe here that even in the dry season, some stations in Bududa experienced significant deformation. This could be attributed to the soil characteristics in these areas, where evaporation of the soil moisture follows a collapse of soils due to larger spaces in the soil left after evaporation.

February to June 2019, most of the stations were stable except for NAKA, BUDU and BUSH. This period coincides with the long-wet season in Bududa and this could imply that the stations in other places have a high saturation rate compared to points in NAKA, BUDU and BUSH. The soils there absorb much water before reaching a threshold for deformation to occur.

\subsection{Discussions}

In this research, a landslide inventory was carried out in Bududa to map out the landslide scars to identify areas to install the GPS monitor stations. GPS monitor 
stations were then built ensuring that stations were in places with good satellite coverage and clear of obstacles. Campaign GPS observations were then made on the monitor stations from June 2018 to June 2019, which is in June 2018, September 2018, November 2018, February 2019 and June 2019. Ground deformation was observed at all the GPS stations, however, the ground deformation magnitudes varied from station to station. The deformation variation was in relation to the type of landslides, whether large, deep rotational or small, shallow translational [7] [28] [29] [30] [31] [32]. Areas in the western region that experienced large deep rotation landslides experienced lower deformation magnitudes than the eastern region which experiences small, shallow translational landslides. The central region experienced deformation but landslides have not been reported in this area and it could be due to the less steep slopes compared to the eastern and western regions [31]. Points with low deformation magnitudes were observed in areas with low slopes in low lying areas and vegetated areas while places with steep and cultivated slopes experienced high deformation magnitudes [14] [33] [34]. Low deformation magnitudes were also observed in areas that had recently experienced landslides. This could be due to the remaining of stable soils after a landslide occurs [4]. When a landslide happens, unstable topsoil is washed away and stable soils remain. It takes time for such areas to become unstable due to landcover change, population growth, farming practices, and rainfall patterns. Ground deformation magnitudes varied within the observation period and this could be due to the change in seasons from wet to dry [36].

The GPS positioning was reliably done for most of the points and relevant information on deformation magnitude achieved. The campaign method of GPS positioning is affordable as cost of setting up is minimal, as only stations are fixed and there is no need to have electricity and personnel to continually operate and manage the station as is the case when an active station is used. The observation period was short due to the length of the project and funds available at the time. Even though the observation was only from June 2018 to June 2019, a good account is given of the deformation characteristics in Bududa. Further observation to about two and half years and more would improve the reliability of the GPS campaign [15] [16] [17].

\section{Conclusion and Recommendations}

The deformation patterns as observed from the GPS measurements in Bududa are very complex. It is observed that deformation is high, in the east, north and height reaching $0.076,0.067$ and $0.078 \mathrm{~m}$ in twelve months. Most of the stations experienced significant deformation not only in a year but also within the year. Some stations appear to be stable when an annual assessment is done but experience significant deformation within the year. Deformation is observed to vary within the year, and annual monitoring will not explicitly describe the district's deformation patterns. Deformation is further observed to occur both during the 
wet and dry seasons; this is attributed to the complex and different deformation mechanisms during the wet and dry seasons. In the short term, Campaign GPS can give a preliminary insight into stable and unstable areas in landslide susceptible areas.

Deformation measurement predicts unstable slopes and may indicate the structures that could be constructed or re-enforced to mitigate a possible future landslide's adverse effects. The GPS technique can reliably measure ground deformation at points where the instruments have been installed. The GPS stations should, however, be selected carefully, otherwise the measured deformation will not be representative of the deformation plane. In selecting suitable locations to place the GPS stations, care should be taken, because the GPS stations could be washed away when a landslide event happens. The installation of the stations should, however, be close to landslide scars and ground cracks to reliability estimate landslide related deformation. Campaign GPS measurement is sufficient to indicate how unstable slopes are. Care should however be taken to ensure that instrument set up bias is minimal by ensuring that the instruments used and instrument height setting are the same throughout the observation period. Shorter observations within a year should be considered when campaign observation is used to be able to visualize more deformation patterns in landslide monitoring. The GPS observation period sessions should not be less than 6 hours to reduce the effect of observation bias that propagates into GPS measurements. The GPS should be dual-frequency and there should be strict adherence to standard GPS processing methodologies as has been discussed in this paper. Furthermore, GPS error sources should be reliably modelled out to achieve reliable results.

Data on ground deformation shows unstable sites in the monitored regions. Where the deformation values are high, people should be resettled elsewhere. In places that have medium deformation, mitigation strategies could be implemented. These may include re-enforcement of structures, and planting of trees. Data on deformation, where mitigation measures are applied should follow to assess the effectiveness of the measures. This would significantly reduce landslide hazard risk in monitored areas.

\section{Acknowledgements}

I would like to acknowledge and thank the homesteads in Bududa who availed space for the installation of GPS monitor stations and further protected and maintained the stations throughout the study. Furthermore, I would like to appreciate the communities affected by landslides in Bududa who shared their experiences as here reported in this research. Lastly, I would like to extend my gratitude to DAAD and Makerere University who financially supported this research. It would not be possible to conduct this research without their support.

\section{Conflicts of Interest}

The authors of this paper declare no conflict of interest regarding the publica- 
tion of this paper.

\section{References}

[1] Saro, L. (2019) Current and Future Status of GIS-Based Landslide Susceptibility Mapping: A Literature Review. Korean Journal of Remote Sensing, 35, 179-193.

[2] Gang, M., Nengxiong, X., Jiayu, Q., Bowen, W. and Pian, Q. (2019) A Survey of Internet of Things (IoT) for Geohazard Prevention: Applications, Technologies, and Challenges. IEEE Internet of Things Journal, 7, 4371-4386. https://doi.org/10.1109/JIOT.2019.2952593

[3] Sidle, R.C. and Ochiai, H. (2006) Processes, Prediction, and Land Use American Geophysical Union. American Geophysical Union, Washington DC, 307.

[4] Lynn, H. and Peter, T.B. (2008) The Landslide Handbook: A Guide to Understanding Landslides. US Geological Survey, Reston.

[5] Haque, U., Da Silva, P.F., Devoli, G., Pilz, J., Zhao, B., Khaloua, A., et al. (2019) The Human Cost of Global Warming: Deadly Landslides and Their Triggers (1995-2014). Science of the Total Environment, 682, 673-684. https://doi.org/10.1016/j.scitotenv.2019.03.415

[6] Haque, U., Blum, P., Da Silva, P.F., Andersen, P., Pilz, J., Chalov, S.R., et al. (2016) Fatal Landslides in Europe. Landslides, 13, 1545-1554.

https://doi.org/10.1007/s10346-016-0689-3

[7] Liesbet, J., Olivier, D., Jean, P., Damien, D., Wim, T. and Matthieu, K. (2016) The Rwenzori Mountains, a Landslide-Prone Region? Landslides, 13, 519-536. https://doi.org/10.1007/s10346-015-0582-5

[8] Melanie, J.F. and David, N.P. (2018) Global Fatal Landslide Occurrence from 2004 to 2016. Natural Hazards and Earth System Sciences, 18, 2161-2181. https://doi.org/10.5194/nhess-18-2161-2018

[9] Savvaidis, P.D. (2003) Existing Landslide Monitoring Systems and Technique. From Stars to Earth and Culture, 242-258.

[10] Abidin, H.Z., Andreas, H., Gamal, M., Surono, S. and Hendrasto, M. (2004) Studying Landslide Displacements in Megamendung (Indonesia) Using GPS Survey Method. Journal of Engineering and Technological Sciences, 36, 109-123.

[11] Turen, Y. and Sanli, D.U. (2019) Accuracy of Deformation Rates from Campaign GPS Surveys Considering Extended Observation Session and Antenna Set-Up Errors. Remote Sensing, 11, Article No. 1125. https://doi.org/10.3390/rs11101225

[12] Fritsche, M., Döll, P. and Dietrich, R. (2012) Global-Scale Validation of Model-Based Load Deformation of the Earth's Crust from Continental Watermass and Atmospheric Pressure Variations Using GPS. Journal of Geodynamics, 59-60, 133-142. https://doi.org/10.1016/j.jog.2011.04.001

[13] Abolmasov, B., Svetozar, M., Branko, J., Marko, P. and Radić, Z. (2015) The Analysis of Landslide Dynamics Based on Automated GNSS Monitoring-A Case Study. In: Lollino, G., Giordan, D., Crosta, G.B., Corominas, J., Azzam, R., Wasowski, J., et al., Eds., Engineering Geology for Society and Territory, Vol. 2, Springer, Cham, 143-146. https://doi.org/10.1007/978-3-319-09057-3_15

[14] Wang, G., Bao, Y., Cuddus, Y., Jia, X., Serna, J. and Jing, Q. (2015) A Methodology to Derive Precise Landslide Displacement Time Series from Continuous GPS Observations in Tectonically Active and Cold Regions: A Case Study in Alaska. Natural Hazards, 77, 1939-1961. https://doi.org/10.1007/s11069-015-1684-Z

[15] Blewitt, G. and Lavallée, D. (2002) Effect of Annual Signals on Geodetic Velocity. 
Journal of Geophysical Research: Solid Earth, 107, ETG 9-1-ETG 9-11. https://doi.org/10.1029/2001JB000570

[16] Bos, M.S., Bastos, L. and Fernandes, R.M.S. (2010) The Influence of Seasonal Signals on the Estimation of the Tectonic Motion in Short Continuous GPS Time-Series. Journal of Geodynamics, 49, 205-209. https://doi.org/10.1016/j.jog.2009.10.005

[17] Williams, S.D.P., Bock, Y., Fang, P., Jamason, P., Nikolaidis, R.M., Prawirodirdjo, L., et al. (2004) Error Analysis of Continuous GPS Position Time Series. Journal of Geophysical Research: Solid Earth, 109, Article No. B03412. https://doi.org/10.1029/2003JB002741

[18] Li, X., Ge, M., Dai, X., Ren, X., Fritsche, M., Wickert, J. and Schuh, H. (2015) Accuracy and Reliability of Multi-GNSS Real-Time Precise Positioning: GPS, GLONASS, BeiDou, and Galileo. Journal of Geodesy, 89, 607-635. https://doi.org/10.1007/s00190-015-0802-8

[19] Dach, R., Lutz, S., Walser, P. and Fridez, P. (2015) Bernese GNSS Software Version 5.2 (Issue November). Astronomical Institute, University of Bern, Bern.

[20] Petit, G. and Luzum, B. (2010) IERS Conventions (2010). Bureau International des Poids et mesures sevres (France).

[21] Pavlov, D.A., Williams, J.G. and Suvorkin, V.V. (2016) Determining Parameters of Moon's Orbital and Rotational Motion from LLR Observations Using GRAIL and IERS-Recommended Models. Celestial Mechanics and Dynamical Astronomy, 126, 61-88. https://doi.org/10.1007/s10569-016-9712-1

[22] Yuan, L., Chao, B.F., Ding, X. and Zhong, P. (2013) The Tidal Displacement Field at Earth's Surface Determined Using Global GPS Observations. Journal of Geophysical Research: Solid Earth, 118, 2618-2632. https://doi.org/10.1002/jgrb.50159

[23] Martens, H.R., Argus, D.F., Norberg, C., Blewitt, G., Herring, T.A., Moore, A.W., et al. (2020) Atmospheric Pressure Loading in GPS Positions: Dependency on GPS Processing Methods and Effect on Assessment of Seasonal Deformation in the Contiguous USA and Alaska. Journal of Geodesy, 94, Article No. 155. https://doi.org/10.1007/s00190-020-01445-w

[24] Steigenberger, P., Boehm, J. and Tesmer, V. (2009) Comparison of GMF/GPT with VMF1/ECMWF and Implications for Atmospheric Loading. Journal of Geodesy, 83, Article No. 943. https://doi.org/10.1007/s00190-009-0311-8

[25] Tregoning, P. and van Dam, T. (2005) Atmospheric Pressure Loading Corrections Applied to GPS Data at the Observation Level. Geophysical Research Letters, 32, Article No. L22310. https://doi.org/10.1029/2005GL024104

[26] Hotta, K. and Iguchi, M. (2017) Ground Deformation Source Model at Kuchinoerabu-jima Volcano during 2006-2014 as Revealed by Campaign GPS Observation. Earth, Planets and Space, 69, Article No. 173. https://doi.org/10.1186/s40623-017-0763-7

[27] Baryla, R., Paziewski, J., Wielgosz, P., Stepniak, K. and Krukowska, M. (2014) Accuracy Assessment of the Ground Deformation Monitoring with the Use of GPS Local Network: Open Pit Mine Koźmin Case Study. Acta Geodynamica et Geomaterialia, 11, 317-324. https://doi.org/10.13168/AGG.2014.0013

[28] Kitutu, M.G., Muwanga, A., Poesen, J. and Deckers, J.A. (2009) Influence of Soil Properties on Landslide Occurrences in Bududa District, Eastern Uganda. African Journal of Agricultural Research, 4, 611-620.

[29] Claessens, L., Knapen, A., Kitutu, M.G., Poesen, J. and Deckers, J.A. (2007) Modelling Landslide Hazard, Soil Redistribution and Sediment Yield of Landslides on the Ugandan Foot Slopes of Mount Elgon. Geomorphology, 90, 23-35. 
https://doi.org/10.1016/j.geomorph.2007.01.007

[30] Kitutu, M.G., Muwanga, A., Poesen, J. and Deckers, J.A. (2011) Farmer's Perception on Landslide Occurrences in Bududa District, Eastern Uganda. African Journal of Agricultural Research, 6, 7-18.

[31] Mugagga, F., Kakembo, V. and Buyinza, M. (2011) A Characterisation of the Physical Properties of Soil and the Implications for Landslide Occurrence on the Slopes of Mount Elgon, Eastern Uganda. Natural Hazards, 60, 1113-1131. https://doi.org/10.1007/s11069-011-9896-3

[32] Gorokhovich, Y., Doocy, S., Walyawula, F., Muwanga, A. and Nardi, F. (2013) Landslides in Bududa, Eastern Uganda: Preliminary Assessment and Proposed Solutions. In: Margottini, C., Canuti, P. and Sassa, K., Eds., Landslide Science and Practice, Springer, Berlin, Heidelberg, 145-149.

https://doi.org/10.1007/978-3-642-31337-0_19

[33] Sun, D.M., Li, X.M., Feng, P. and Zang, Y.G. (2016) Stability Analysis of Unsaturated Soil Slope during Rainfall Infiltration Using Coupled Liquid-Gas-Solid Three-Phase Model. Water Science and Engineering, 9, 183-194.

https://doi.org/10.1016/j.wse.2016.06.008

[34] Pramusandi, S., Rifa'i, A. and Suryolelono, K.B. (2015) Determination of Unsaturated Soil Properties and Slope Deformation Analysis Due to the Effect of Varies Rainfall. Procedia Engineering, 125, 376-382. https://doi.org/10.1016/j.proeng.2015.11.090

[35] Orense, R.P. (2004) Slope Failures Triggered by Heavy Rainfall. Philippine Engineering Journal, 25, 73-90.

[36] Khalid, N.H.N., Usman, F. and Omar, R.C. (2018) Effect of Rainfall to the Groundwater and Soil Displacement. International Journal of Engineering Research and Technology, 11, 439-450.

[37] Haddad, Z.S., Meagher, J.P., Adler, R.F., Smith, E.A., Im, E. and Durden, S.L. (2004) Global Variability of Precipitation According to the Tropical Rainfall Measuring Mission. Journal of Geophysical Research: Atmospheres, 109, Article No. D17103. https://doi.org/10.1029/2004JD004607 